SAND95-1126

Distribution

Unlimited Release

Category UC-742

Printed July 1995

\title{
Control of the Reactant Ion Chemistry for the Analysis of Explosives by Ion Mobility Spectroscopy
}

\author{
Philip J. Rodacy \\ Explosive Subsystems and Materials Department \\ David Ingersoll \\ Battery Programs Department \\ Sandia National Laboratories \\ Albuquerque, NM 87185-5800
}

\begin{abstract}
Changes in the reactant ion composition in the ion mobility spectrometer (IMS) can result in a change in the ionization processes occurring in the ionization region, ultimately leading to an altered instrumental response for the analyte, and exacerbating the problem of qualitative and quantitative analysis. Some species are very susceptible to changes in reactant ions, while other species are relatively unaffected. These types of behavior are observed for two common explosives, namely, hexahydro-1,3,5-trinitro1,3,5-triazine (RDX) and 1,3,5-trinitrotoluene (TNT), respectively.
\end{abstract}

To control the reactant ion composition, and hence the gas phase chemistry, it is necessary to control the composition of gases present in the ionization region of the IMS. A series of modifications are described for the PCP Phemto-Chem 100 IMS that afford the requisite control. The effectiveness of these modifications for analysis of RDX and TNT are described and contrasted with that observed for the . unmodified system. 
Intentionally Left Blank 


\section{DISCLAIMER}

Portions of this document may be illegible in electronic image products. Images are produced from the best available original document. 


\section{DISCLAIMER}

This report was prepared as an account of work sponsored by an agency of the United States Government. Neither the United States Government nor any agency thereof, nor any of their employees, makes any warranty, express or implied, or assumes any legal liability or responsibility for the accuracy, completeness, or usefulness of any information, apparatus, product, or process disclosed, or represents that its use would not infringe privately owned rights. Reference herein to any specific commercial product, process, or service by trade name, trademark, manufac: turer, or otherwise does not necessarily constitute or impiy its endorsement, recommendation, or favoring by the United States Government or any agency thereof. The views and opinions of authors expressed herein do not necessarily state or reflect those of the United States Government or any agency thereof. 


\section{Contents}

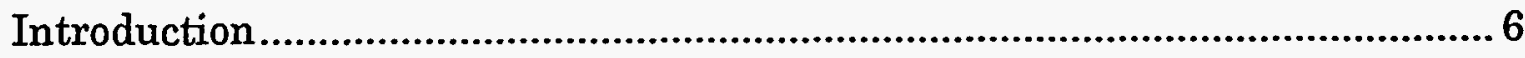

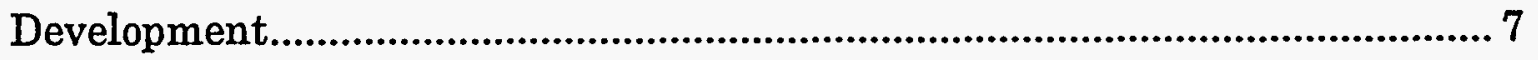

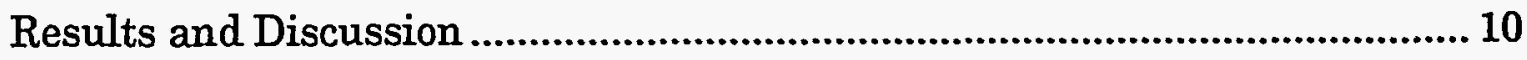

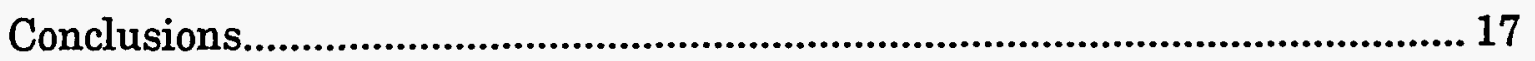

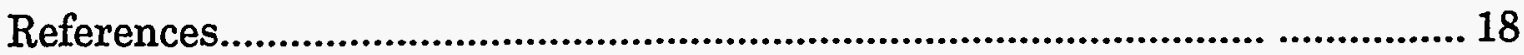

\section{Illustrations}

1. IMS inlet modified with "cross" to control gas flows.............................. 8

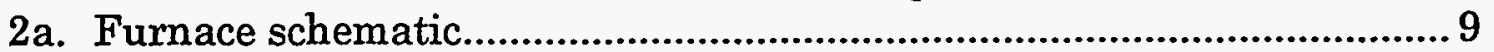

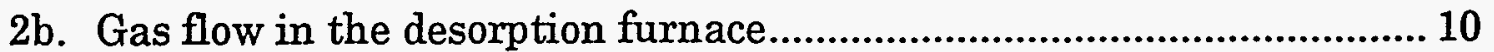

3a. IMS response while aspirating room air ................................................ 11

$3 \mathrm{~b}$. IMS response while aspirating room air; aerosol duster being used elsewhere in room ...................................................................... 11

3c. IMS response while aspirating room air; aerosol glass cleaner being used elsewhere in room ................................................................. 11

4a. Ultra high purity nitrogen being aspirated into the IMS .................... 12

4b. Aerosol duster blowing directly at 4-way cross....................................... 12

5a. Spectrum of TNT with laboratory air in the IMS .................................. 13

5b. Spectrum of TNT with laboratory air in IMS; aerosol duster being used elsewhere in the room ........................................................ 13

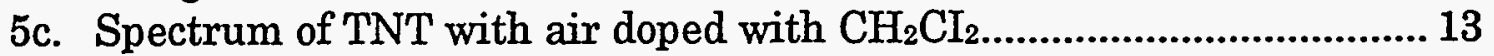

6a. Spectrum of room air being aspirated into the IMS .............................. 14

6b. Spectrum of RDX being aspirated along with room air. ....................... 14

7. Peak Intensities Change With Changing RDX Concentration ............. 15

8. Air Doped With Methylene Chloride .................................................... 16

9. Spectrum of RDX being aspirated into the IMS. ...................................... 16 


\section{INTRODUCTION}

For a variety of reasons, including its ease of use and high sensitivity, an increased interest is being shown in the use of ion mobility spectrometry (IMS) for the qualitative and quantitative analysis of explosives. An IMS is basically a time-offlight mass spectrometer that operates at atmospheric pressure. The sample of interest, most often a gaseous species or solution, is introduced into the source region of the instrument, where it is ionized. The ionized species are then accelerated down the drift region of the instrument where they are separated on the basis of mass, charge, and size, among other things. Ultimately the ions are detected, with the resulting signal being proportional to the quantity of material present.

In the ionization region of the PCP Phemto-Chem 100 instrument, $63 \mathrm{Ni}$ decays through beta emission, and an electron having a maximum energy of approximately $65 \mathrm{keV}$ results. Through a series of collisions and interactions with the gaseous species present in the ionization region, thermal electrons, and a variety of positive and negative ions, known as reactant ions, are produced. With air present in the instrument, the thermal electrons are not usually detected since they react with air to form the reactant ions. Some of the reactant ions that are produced include $\left(\mathrm{H}_{2} \mathrm{O}\right)_{n} \mathrm{H}^{+},\left(\mathrm{H}_{2} \mathrm{O}\right)_{n} \mathrm{O}^{-}$, and $\left(\mathrm{H}_{2} \mathrm{O}\right)_{n} \mathrm{CO}_{3}^{-}$[1].

Ionization of the analyte most often occurs through gas phase reaction with the reactant ions. A number of possible reaction mechanisms for the formation of negative ions have been identified [1-3], including

electron capture;

$$
A+\mathrm{e}^{-} \rightarrow \mathrm{A}^{-}
$$

charge transfer;

$$
A+R^{-} \rightarrow A^{-}+R
$$

proton transfer;

$$
\mathrm{A}+\mathrm{R}^{-} \rightarrow \mathrm{A}^{-}+\mathrm{RH}
$$

and an addition reaction;

$$
A+R^{-} \rightarrow \mathrm{AR}^{-}
$$

where $A$ is the analyte and $R$ represents the reactant ions.

In addition, charged species derived from the analyte can be formed by dissociation of the products created in these initial reactions [1-4]. For example, dissociative 
electron capture, which is electron capture followed by dissociation of the charged intermediate, is illustrated in Eq. 5 [3].

$$
\mathrm{A}+\mathrm{e}^{-} \rightarrow\left(\mathrm{A}^{-}\right) \rightarrow \mathrm{B}^{-}+\mathrm{C}
$$

Upon consideration of the various ionization mechanisms, it is apparent that a change in the composition of the gaseous species present in the ionization region of the instrument can lead to a variation in the product distribution. During normal operation of the IMS, laboratory air is drawn into the instrument, along with any volatile compounds that may be present in the atmosphere. For example, if a laboratory operation utilizing compounds having a high vapor pressure is in progress, these species could be aspirated into the instrument, resulting in the formation of other reactant ions and ultimately leading to an altered instrument response. Furthermore, the presence of more than one reactant ion may result in formation of more than one charged species derived from the analyte. As a consequence, the total signal obtained is divided between the various species generated. This could conceivably result in a lowered instrumental response for each, at least in comparison to the response observed when only a single ionized specie is produced.

We have observed both types of behavior in our laboratory when using the IMS for the qualitative and quantitative analysis of explosives solutions. For this reason, we have configured the instrument so that we can maintain control of the gas composition in the instrument and, as a consequence, control the gas phase chemistry occurring. This allows one to tailor the environment in the instrument to achieve an optimized instrument response. With these modifications, it is possible to perform a series of experiments that can lead to an increased understanding of the gas phase chemistry. The effect of the gas composition on the instrumental response, the modifications that we have made to the system to control the gas phase chemistry, and the performance characteristics of the modified system are described. These studies were performed using two explosives, 1,3,5-trinitrotoluene (TNT), and hexahydro-1,3,5-trinitro-1,3,5-triazine (RDX).

\section{EXPERIMENTAL}

The IMS used for these studies was the PCP PHEMTO-CHEM 100 [4]. As configured by the factory, the outlet ports of the recirculating air pumps and associated cleanup columns are used to deliver air into the drift and ionization regions of the instrument. We disconnected these pumps and vented the IMS into a fume hood. We replaced this factory recirculation system with a gas cylinder and regulator for delivering compressed gas to the drift region of the instrument. The port located at the back of the instrument, which usually supplies gas to the ionization region, was capped using a Swagelok fitting. In this configuration the 
recirculating air pumps are used only to remove gas from the instrument. This configuration allows us to control the gas present in the drift region of the IMS.

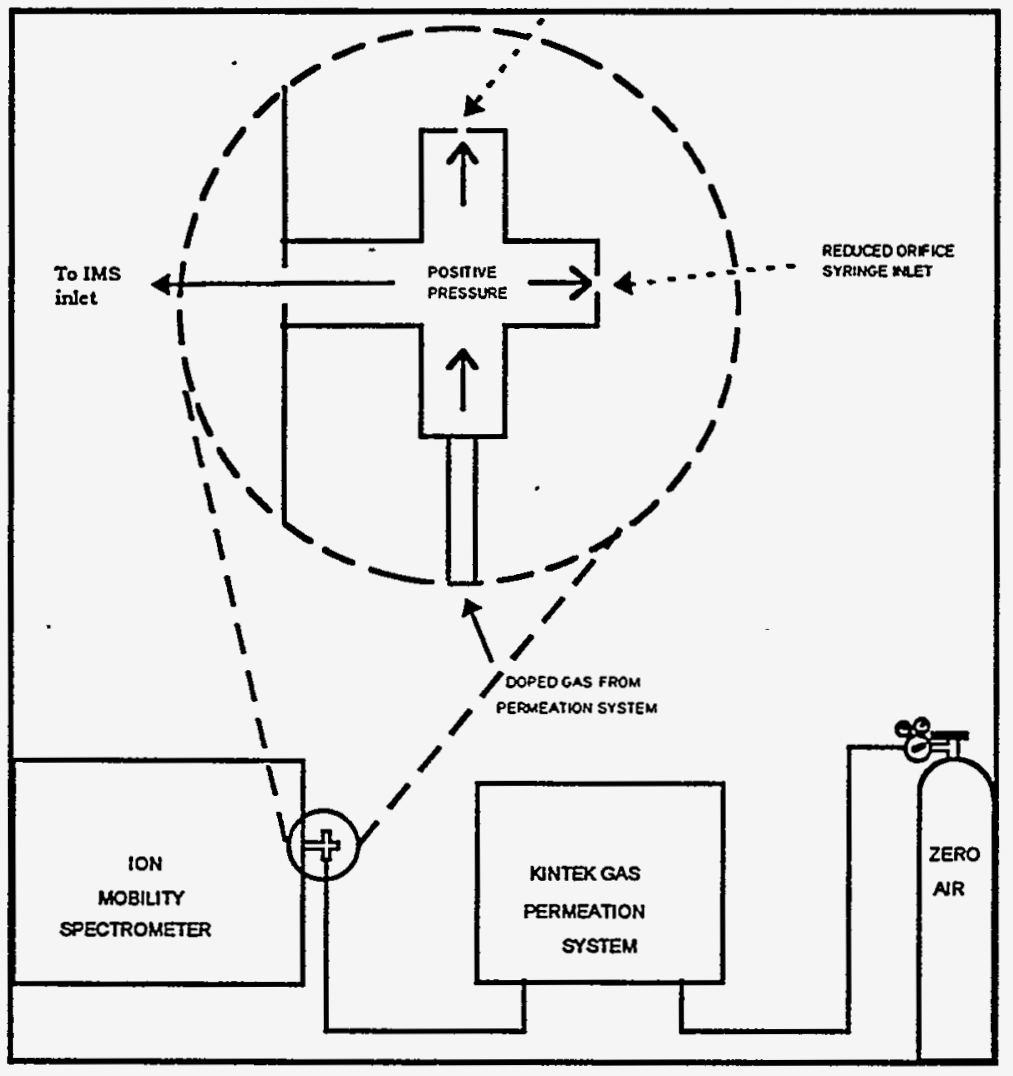

Figure 1. IMS inlet modified with "cross" to control gas flows.
We also modified the instrument to allow us to control the gas being drawn into the IMS through the sample inlet port. For analysis of solutions, a $1 / 4$ inch Swagelok 4-way cross was fitted onto the instrument inlet. A length of 1/8 inch OD copper tubing was connected to one of the transverse ports on this fitting, and was used to supply the controlled atmosphere to the inlet of the IMS. The other transverse port was fitted with a short length of $1 / 4$ inch OD stainless steel tubing that was crimped to provide a reduced orifice. The final port, which was aligned with the axis of the IMS drift region, was fitted with a PCP supplied

Swagelok fitting that has a small hole in it. This port is used for insertion of the syringe needle into the instrument for sample injection. The rate of gas flow into the 4-way cross is in excess of the $200 \mathrm{ml} \mathrm{min} .^{-1}$ that is drawn into the IMS. The excess is vented through the needle inlet and the reduced orifice. In this way, room air and potential contaminants are excluded, and the gas that is drawn into the instrument is that supplied to the 4-way cross. This system is shown in Figure 1.

The composition of the gas delivered to the inlet port of the IMS was ultra-highpurity (UHP) nitrogen $\left(\mathrm{N}_{2}\right)$ that was doped with a controlled amount of another chemical species. This was done by passing the UHP $\mathrm{N}_{2}$ through a Kin-Tek Model 570 Precision Gas Permeation System. For the studies described here, a gas permeation tube containing methylene chloride was used in the Kin-Tek system. The methylene chloride was delivered to the IMS at a rate of approximately 7.5 egomin. ${ }^{-1}$. 
For collection and analysis of vapor samples, the procedure described by Yelverton [5] was used. This procedure consists of drawing an air sample through a preconcentrator tube, followed by thermal desorption of the sample of interest into the instrument. For the work described here, the preconcentrator tubes were $1 / 4$ inch OD by 6 inch long quartz tubes. A specially designed furnace system that has been thoroughly described elsewhere [6], was used to heat the collection tubes and thermally desorb the sample. Using this system, a well-controlled gas composition is delivered into the heated region of the furnace at a rate greater than the aspiration rate of gas through the preconcentration tube and into the IMS. A diagram of the furnace system is shown in Figure 2a. The gas flow in the furnace is shown in Figure $2 b$.

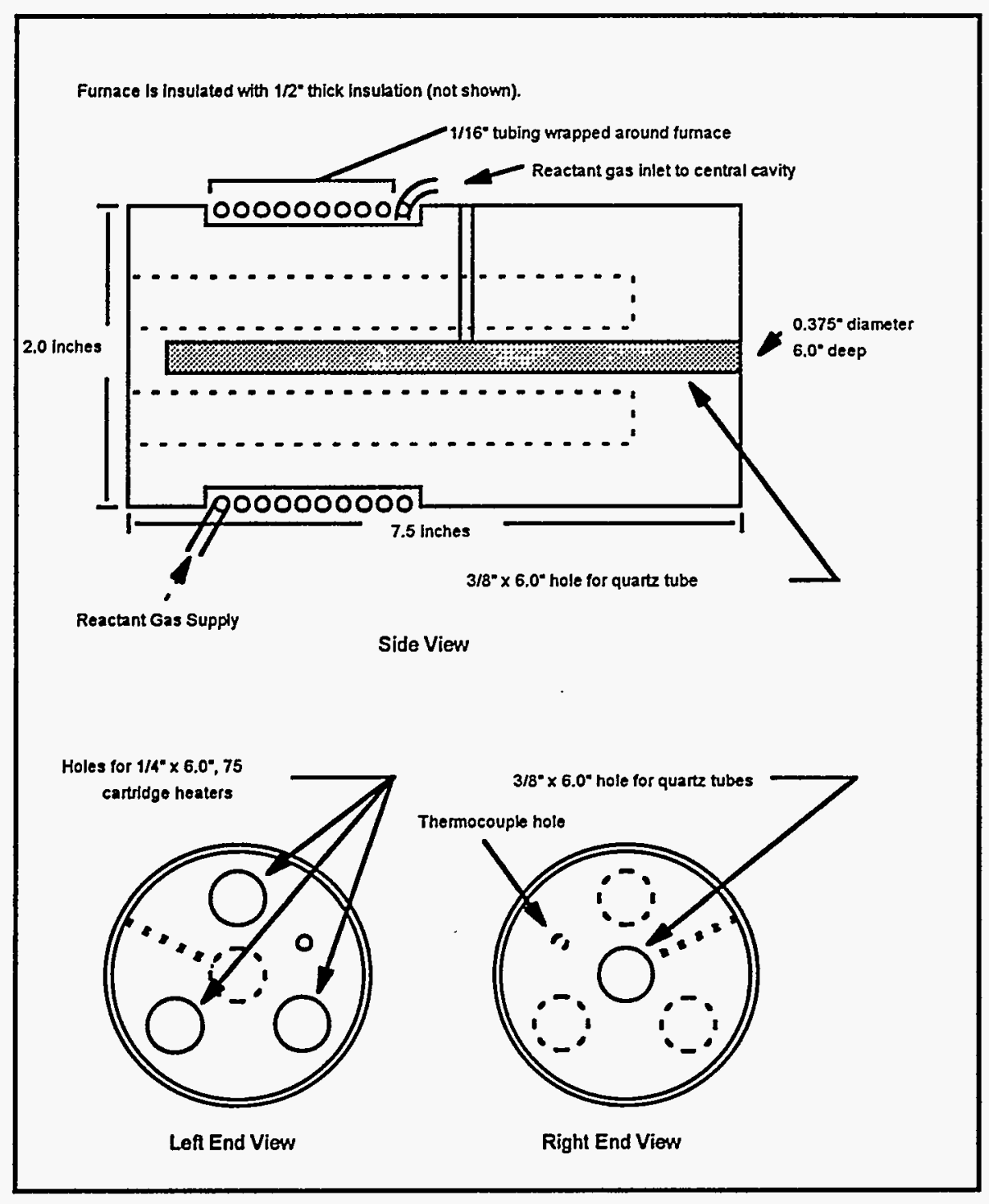

The output from the IMS was monitored using the PCP ASPB-1 Data Acquisition System (PCP, Inc.) and an IBM AT personal computer. In addition, a PCP boxcar integrator connected to a Spectra Physics Chrom Jet integrator was used to monitor the IMS output.

Figure 2a. Furnace schematic 


\section{RESULTS AND DISCUSSION}

\section{CONTROL OF REACTANT IONS}

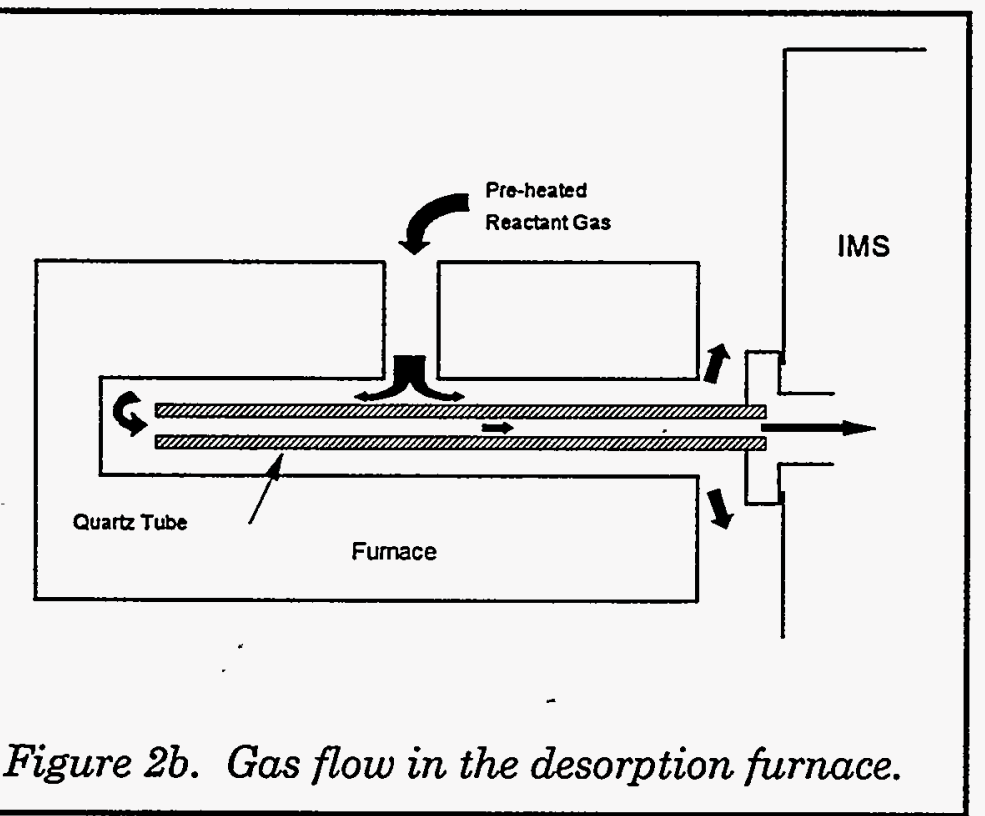

When laboratory air is drawn into the instrument, the species present in the air contribute to the observed instrumental response. Consequently, when an activity occurs that alters the composition of the laboratory air, a change in the instrumental response is observed. This is illustrated in Figures $3 a, 3 b$, and $3 c$, which shows the initial instrument response, the response observed when a printed circuit board is cleaned in the laboratory using a common commercially available duster, and when glass is cleaned in the laboratory using a commercially available aerosol spray cleaner. The chemical species of the aerosol sprays are dispersed throughout the laboratory and aspirated into the instrument, ultimately altering the reactant ion composition. This altered gas composition can lead to an altered response for the species of primary interest, as will be shown. 

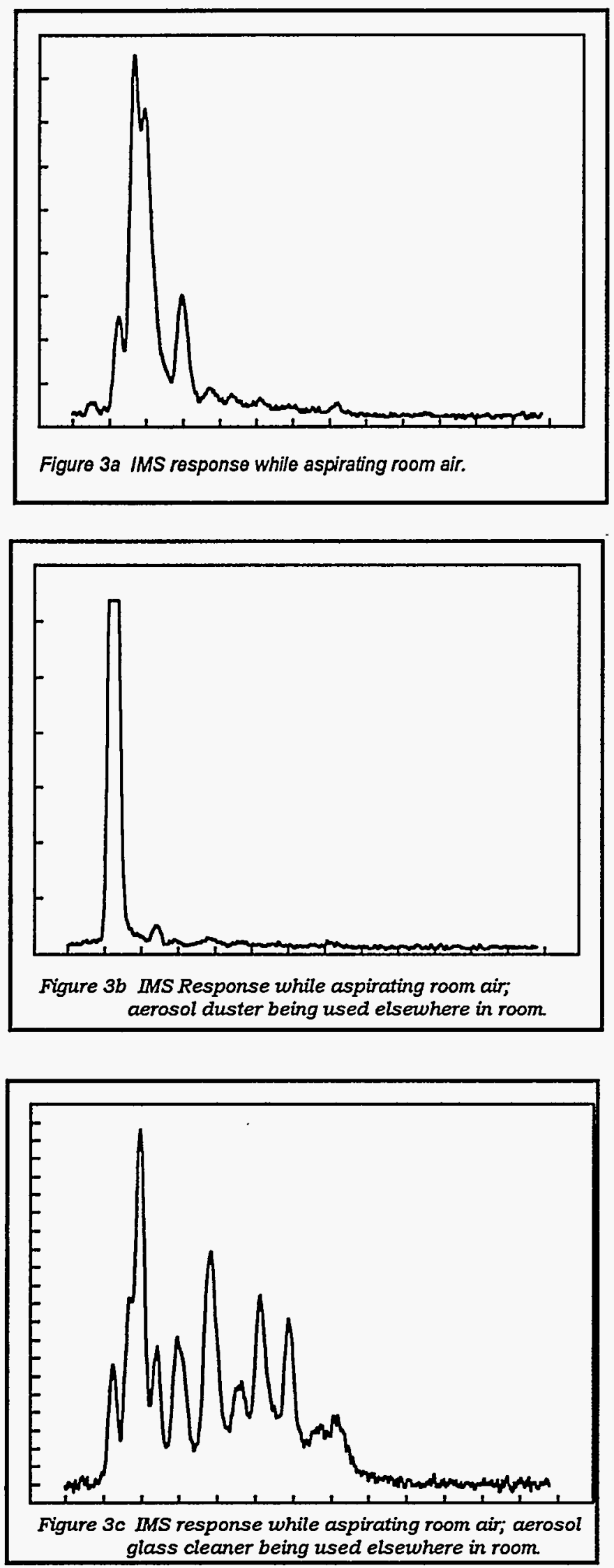

In contrast to this behavior, by making the modifications described here, there is no change in the nature of the reactant ions present in the IMS despite an alteration in the gas composition of the air in the laboratory. When only UHP $\mathrm{N}_{2}$ is being introduced into the system, only one negative ion peak having a short drift time is observed, as shown in Figure 4a. The species responsible for this peak are presumably thermal electrons [7]. When the circuit board aerosol is discharged directly at the 4-way cross on the IMS inlet, a small peak having a drift time of $\approx 6.2 \mathrm{msec}$ is observed as shown in Figure 4b. Despite the severe conditions, the IMS response observed is only slightly affected. Under more realistic conditions when the spray is merely discharged in the room and is not directed at the IMS, there is no perturbation of the instrument response.

For some compounds the charged species produced and detected are, for the most part, unaffected by the composition of reactant ions present in the instrument. An example of one such compound is TNT. As seen in Figure 5, regardless of which reactant ions are present in the instrument or their relative concentration, the same charged species derived from TNT and having a drift time of $\approx 12.2 \mathrm{msec}$ is observed upon injection of a TNT solution into the instrument. This

charged species is believed to be a negatively charged TNT molecule, and not an 
adduct. For these data, ultra zero was used as the drift gas, and the gas being aspirated into the instrument was varied. This resulted in a significant variation

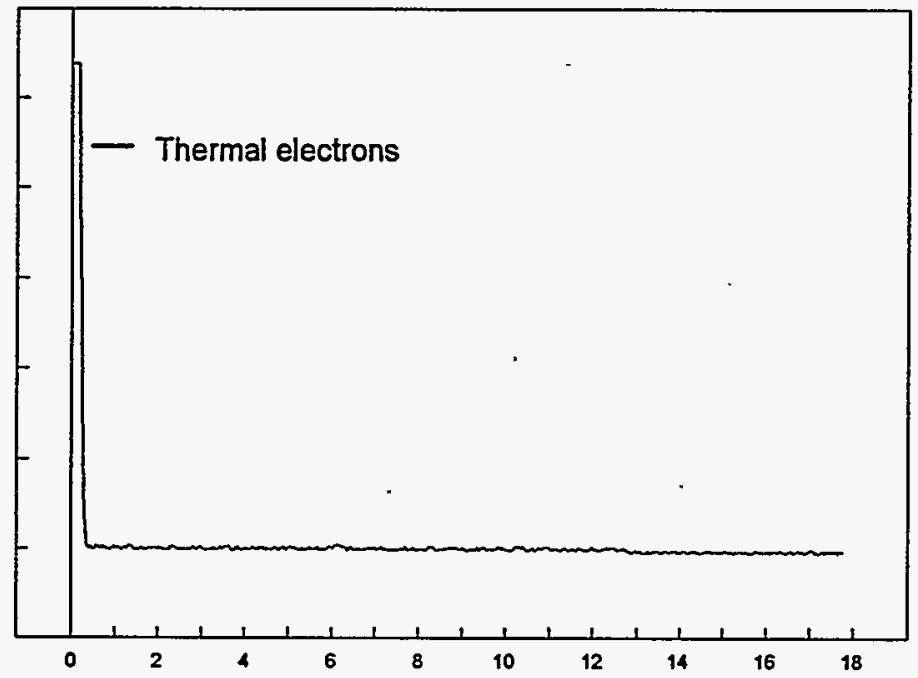

Figure 4a. Ultra high purity nitrogen being aspirated into the IMS in the composition of the reactant ions present. Other than perhaps altering the yield of charged TNT species produced, as will be discussed later in this report, it appears that no benefit is gained by controlling the gas composition of the IMS for analysis of TNT.

In contrast, the response for RDX is affected by the distribution of reactant ions. With laboratory air being aspirated into the IMS and ultra zero air as the drift gas, a number of reactant ions are formed in the instrument, as shown in Figure 6a. When a solution of RDX is introduced into the instrument under these conditions, a number of negatively charged species derived from the parent RDX molecules are produced, as seen in Figure 6b. These

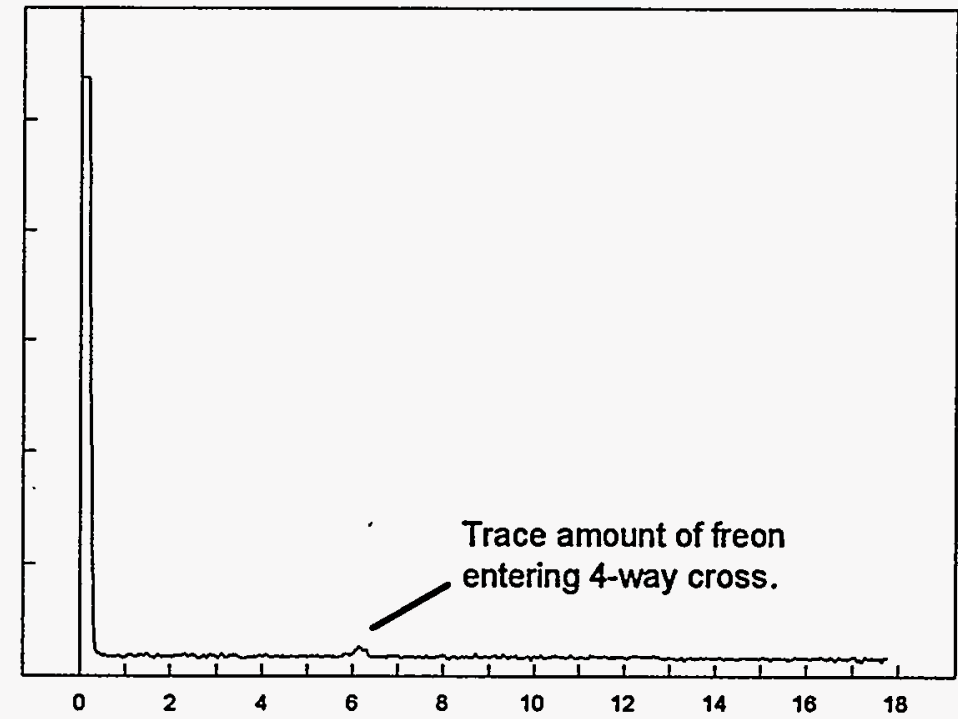

Figure 4b. Aerosol duster blowing directly at 4-way cross. species are believed to be adducts formed from $R D X$ and the various reactant ions present in the system according to Equation 4, although this has not been definitively shown to be the case. 

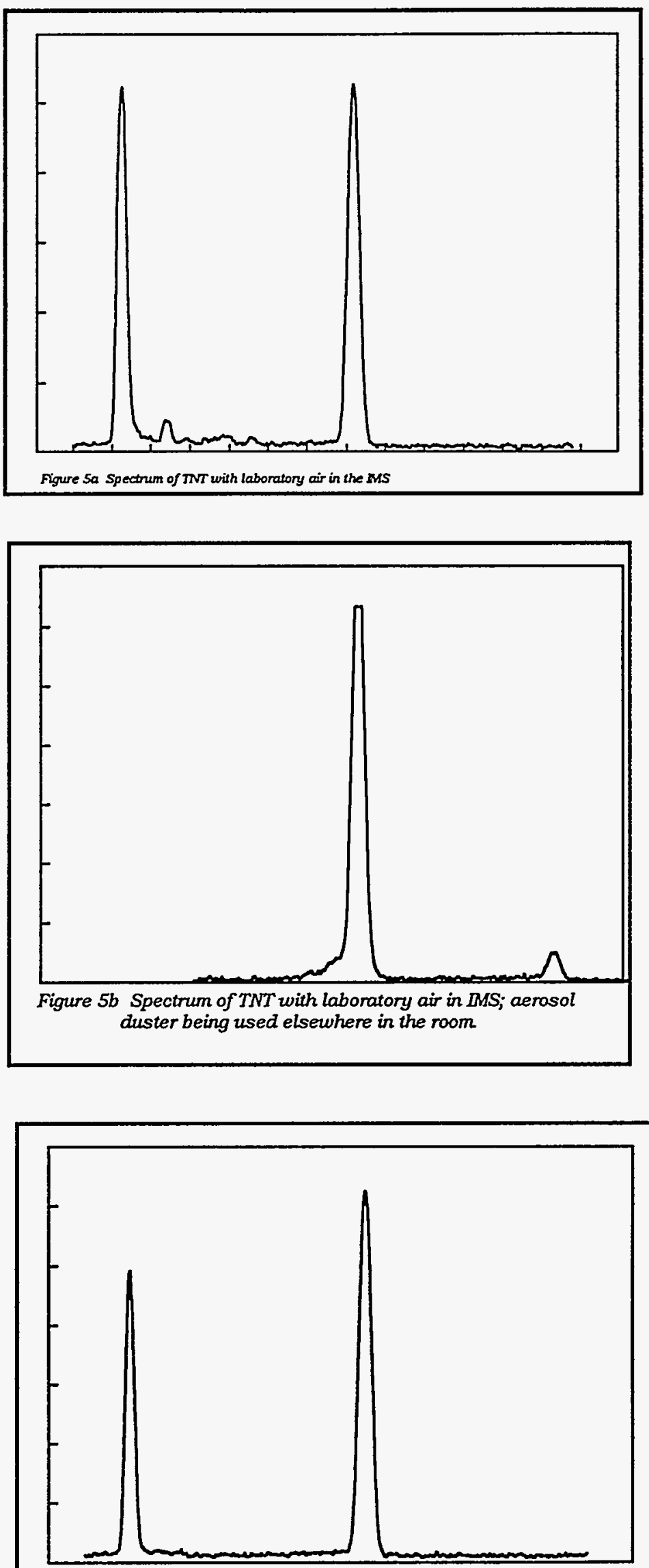

Figure $5 c$ Spectrum of TNT with air doped with $\mathrm{CH}_{2} \mathrm{Cl}_{2}$. 

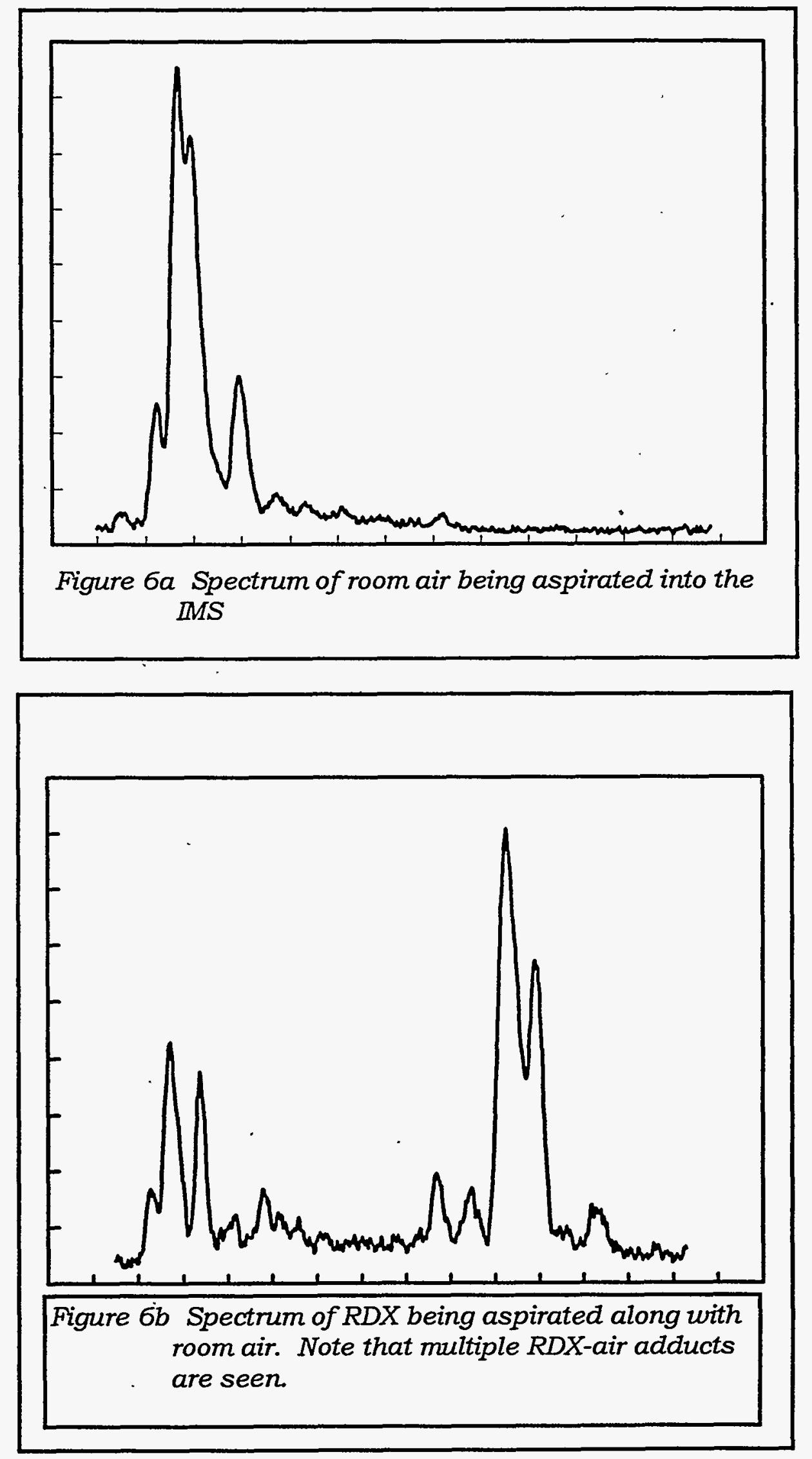

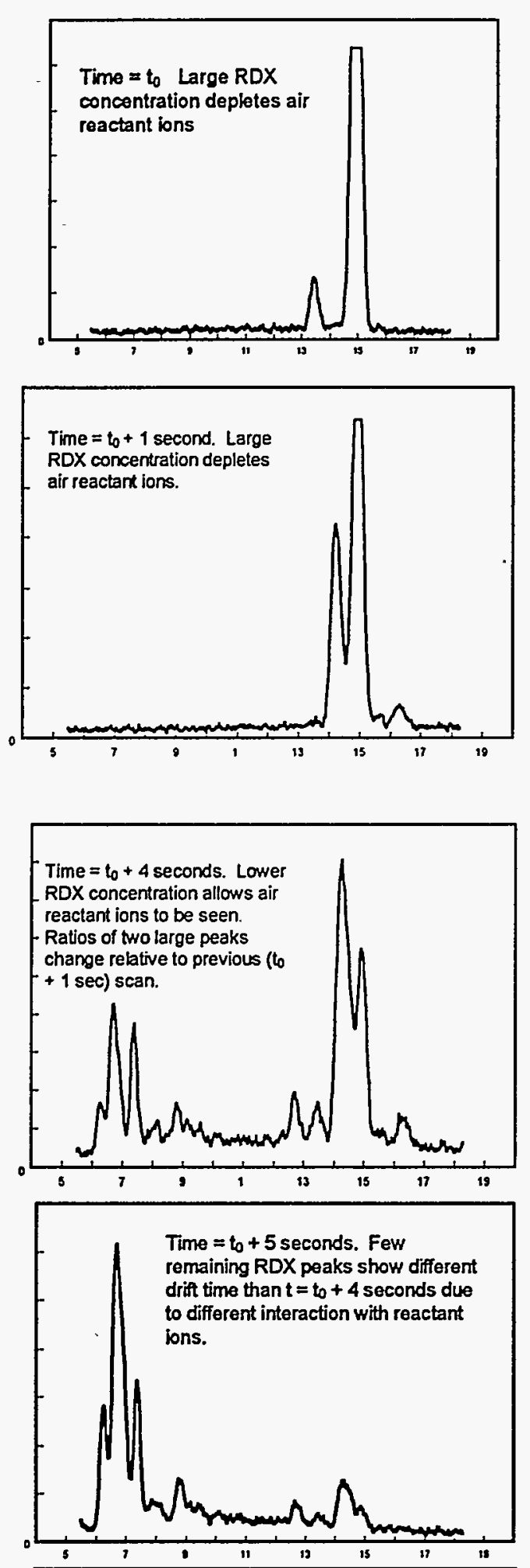

Figure 7. Peak intensities change with changing $R D X$ concentration.
In addition to observing these numerous charged adducts, we have also observed that their relative concentration, as well as the addition of new RDX adducts changes during the course of analysis. This is illustrated in Figure 7, which shows a series of successive waveforms collected at approximately one second intervals after injection of the RDX solution into the IMS. (Each waveform consists of a sum of 25 successive scans acquired at $25 \mathrm{msec}$ intervals.) This behavior presumably results from the changing reactant ion concentration and make quantitation difficult, if not impossible. It is believed that this behavior is a manifestation of the dynamics of the reactions between RDX and the various reactant ions present.

By controlling the gas composition and introducing methylene chloride into the IMS, predominantly one reactant ion is observed, as seen in Figure 8. In this case zero air doped with methylene chloride is the gas being delivered to the sample inlet port and UHP N2 is used as the drift gas. Although other species present, such as $\mathrm{H}_{2} \mathrm{O}$ and $\mathrm{O}_{2}$, could generate reactant ions, they do not, presumably as a result of the electronegativity of methylene chloride in comparison to these other species. 


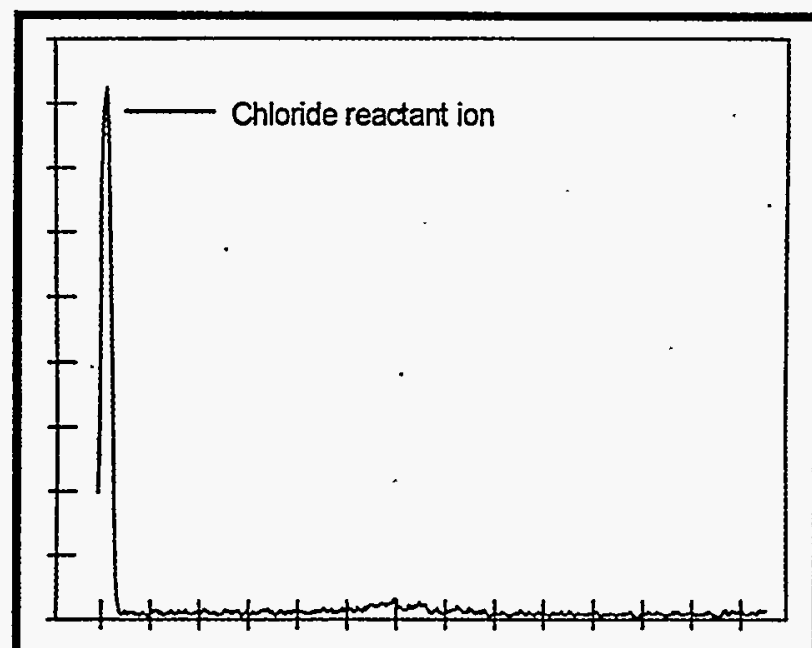

Fgure 8. Air doped with methylene chloride.

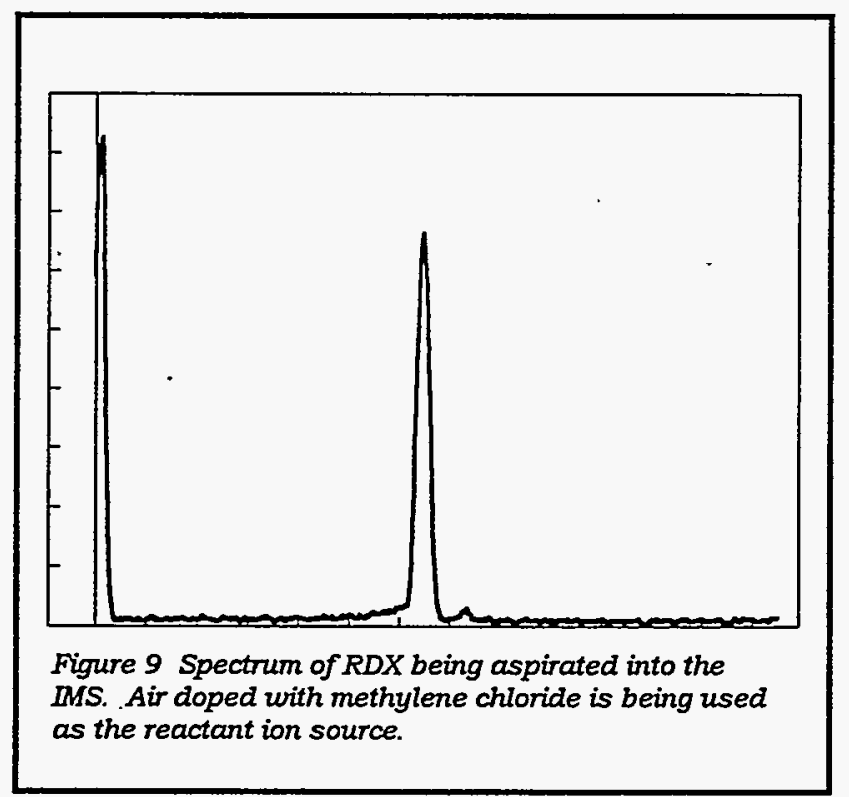

Under these conditions, namely with a single negative reactant ion present in the system, only one negatively charged species derived from RDX is observed upon injection of an RDX solution, as seen in Figure 9 [8]. During the early part of analysis, when there is still only a single primary reactant ion, only one charged species derived from RDX is observed. As the amount of RDX in the system increases, the signal observed from the methylene chloride derived reactant ion is seen to decrease. If the amount of RDX present is of sufficient quantity that the methylene chloride is depleted, reactant ions derived from air are observed, and a series of peaks corresponding to charged moieties derived from the RDX - air interactions (Fig. 6b) appear.

It was previously mentioned that it is possible to affect the yield of charged species produced by varying the reactant ions. We monitored the instrumental response when methylene chloride was introduced into instrument at a rate of approximately 7.5

ug॰min.-1 with UHP N2 being used as the drift gas, and with the methylene chloride being delivered to the 4-way cross using either UHP $\mathrm{N}_{2}$ or ultra zero air.

When UHP $\mathrm{N}_{2}$ is used, two peaks are observed. One of these has a drift time of approximately $0.14 \mathrm{msec}$ and is due to thermal electrons. The other has a drift time of $6.26 \mathrm{msec}$ and is derived from methylene chloride. One of the interesting observations made is that despite the presence of a large amount of a compound having a high electron affinity, thermal electrons can still be observed. When ultra zero air is used in place of UHP $\mathrm{N}_{2}$ to deliver the methylene chloride to the IMS, the resulting spectrum reveals that the peak at $6.26 \mathrm{msec}$ is significantly larger. This 
indicates that the yield of charged species derived from methylene chloride under these conditions is larger than that observed when UHP $\mathrm{N}_{2}$ is used.

A number of explanations based on the kinetics and mechanisms of the gas phase reactions occurring can be advanced which account for this behavior. However, the only definitive statement that can be made is that the yield of charged species derived from methylene chloride is greater with zero air present, than with UHP $\mathrm{N}_{2}$.

The variation in the yield of charged species produced under varying gas compositions also effects the response observed for the explosives. For these studies, UHP $\mathrm{N}_{2}$ was used as the drift gas. Only the gas being delivered to the 4way cross on the inlet was varied. These gases consisted of UHP $\mathrm{N}_{2}$, UHP $\mathrm{N}_{2}$ doped with methylene chloride, zero air, zero air doped with methylene chloride, and lab air.

With UHP $\mathrm{N}_{2}$, no charged species derived from TNT were observed. With methylene chloride doped UHP $\mathrm{N}_{2}$, only a very small signal was observed. With zero air present, a large signal for TNT was observed, which displayed its normal time evolution response. In the case of zero air doped with methylene chloride and lab air, the response observed was similar to that observed for zero air.

These data graphically demonstrate that the carrier reactant) gas composition can significantly affect the yield of charged species produced.

\section{CONCLUSION}

The effect of the gas composition in the ionization region of the IMS on the yield and species distribution of products generated upon analysis of TNT and RDX has been demonstrated. In order to control these effects, a system for controlling the gas composition in the IMS, and hence the reactant ions and gas phase chemistry, has been described. The utilization of this system and the benefits to be derived from its use have been described for the detection and analysis of explosives. Although the behavior of TNT and RDX with methylene chloride present was emphasized, it should not be assumed that the set of conditions utilized is optimal for their analysis. In fact, it seems clear that much additional work needs to be completed before a true understanding of the gas phase chemistry and an optimal set of conditions can be given. However, with the modifications described here, these studies can be performed simply and easily. 


\section{REFERENCES}

1) Spangler and M. J. Cohen, Plasma Chromatography, T. W. Carr, Ed., Plenum Publishing Corp., 1984, pp. 1-41.

2) E. Spangler, D. N. Campbell, K. N. Vora, and J. P. Carries, ISA Trans., 1984, $23,17$.

3) G. E. Spangler and J. P. Carrico, Int. J. Mass Spec. and Ion Phys., 1983, 52, 267.

4) PCP Inc., West Palm Beach, Florida.

5) B. J. Yelverton, J. Energetic Materials, 1988, 6, 73.

6) P. J. Rodacy and D. Ingersoll, Collection, Handling, Transportation, and Thermal Desorption of Explosive Vapors Using Quartz Collection Tubes, Sandia National Laboratories, Internal Document SAND90-1326, 1990.

7) F. W. Karasek and G. E. Spangler, Electron Capture, Theory and Practice in Chromatography, J. Chrom. Library Vol. 20, A. Zlatkis and C. F. Poole, Eds., Elsevier Scheitific Publishing Co., NY, 1981, pp. 377-405.

\section{CREDIT}

Financial support for this work was received from the Federal Bureau of Investigation under Contract JBN3869750, the Federal Aviation Administration under Contract DTFA03-A-40009, and the Department of Energy under Contract DE-ACO4-76DP00789. 


\section{DISTRIBUTION}

1 Dr. Dean Fetterolf

FBI Academy

Forensic Science Research \& Training Center

Quantico, VA 22135

1 Dr. Frederic Whitehurst

Federal Bureau of Investigation

Laboratory Division

JEH Building

10th \& Pennsylvania, N.W.

Washington, DC 20535

1 Dr. John Hobbs

Transportation Systems Center

Department of Transportation

Kendall Square

DTS-75

Cambridge, MA 02142

1 MS 1452 J. G. Harlan, 2652

10 MS 1452 P. J. Rodacy, 2652

1 MS 1452 S. Klassen, 2652

1 MS 1452 E. Knecht, 2652

1 MS $1452 \quad$ P. Leslie, 2652

10 MS 0613 D. Ingersoll, 2206

1 MS 0782 D. Hannum, 5845

1 MS 9018 Central Technical Files, 8523-2

5 MS 0899 Technical Library, 13414

1 MS 0619 Print Media, 12615

2 MS 0100 Document Processing, 7613-2

for DOE/OSTI

1 MS 9116 J. A. Wackerly, 8534 